\title{
Habitat selection, facilitation, and biotic settlement cues affect distribution and performance of coral recruits in French Polynesia
}

\author{
Nichole Price
}

Received: 10 June 2009 / Accepted: 26 January 2010 / Published online: 19 February 2010

(C) The Author(s) 2010. This article is published with open access at Springerlink.com

\begin{abstract}
Habitat selection can determine the distribution and performance of individuals if the precision with which sites are chosen corresponds with exposure to risks or resources. Contrastingly, facilitation can allow persistence of individuals arriving by chance and potentially maladapted to local abiotic conditions. For marine organisms, selection of a permanent attachment site at the end of their larval stage or the presence of a facilitator can be a critical determinant of recruitment success. In coral reef ecosystems, it is well known that settling planula larvae of reefbuilding corals use coarse environmental cues (i.e., light) for habitat selection. Although laboratory studies suggest that larvae can also use precise biotic cues produced by crustose coralline algae (CCA) to select attachment sites, the ecological consequences of biotic cues for corals are poorly understood in situ. In a field experiment exploring the relative importance of biotic cues and variability in habitat quality to recruitment of hard corals, pocilloporid and acroporid corals recruited more frequently to one species of CCA, Titanoderma prototypum, and significantly less so to other species of CCA; these results are consistent with laboratory assays from other studies. The provision of the biotic cue accurately predicted coral recruitment rates
\end{abstract}

Communicated by Jeff Shima.

\section{N. Price}

Ecology, Evolution, and Marine Biology Department,

University of California, Santa Barbara, CA 93106, USA

\section{Present Address:}

N. Price $(\square)$

Center for Marine Biodiversity and Conservation,

Marine Biology Research Division,

Scripps Institute of Oceanography,

La Jolla, CA 92093, USA

e-mail:nprice@ucsd.edu across habitats of varying quality. At the scale of CCA, corals attached to the "preferred" CCA experienced increased survivorship while recruits attached elsewhere had lower colony growth and survivorship. For reef-building corals, the behavioral selection of habitat using chemical cues both reduces the risk of incidental mortality and indicates the presence of a facilitator.

Keywords Crustose coralline algae $\cdot$ Heterospecific attraction

\section{Introduction}

In patchy landscapes, habitat specialists can potentially choose to occupy locations that maximize their fitness. While habitat generalists might find a location quickly, specialists can incur costs for the energy spent assessing and searching appropriate habitat types (Morris 2003), especially if suitable locations are diffuse. Therefore, the distribution of specialists that favors fitness is a function of the balance between the costs of searching for suitable sites and the benefits of choosing a superior location (Rosenzweig 1981; Shachak and Brand 1988; Storch and Frynta 1999). For organisms that exhibit high site fidelity, the consequences of selecting poor habitat can be extreme enough to favor specialization, even when suitable habitat is limiting (Moran 1985; Smoothey and Chapman 2007). Environmental or biotic cues that allow individuals to quickly assess habitat quality can greatly aid habitat selection (Monkkonen et al. 1999; Thomson et al. 2003; Stamps and Krishnan 2005). Therefore, the ability to use such cues to discern among habitat types may represent the most important behavioral aspects of the recruitment stage for many habitat specialists and may affect the distribution of adults. 
Two different types of studies are often employed to assess habitat preferences upon settlement: (1) surveys of the association of individuals with different habitats immediately following a settlement event, and (2) manipulations of the availability of different habitat types. For example, in the first approach, recruit abundances are correlated with habitat characteristics (e.g., urchin recruits were correlated with characteristics of intertidal boulders; Smoothey and Chapman 2007), while in the second, settlers are provided with a choice of different habitat types in a controlled experiment (Botero and Atema 1982). Commonly, individuals are monitored through time following settlement to relate subsequent performance to habitat selection. Thus, the fitness benefits of using cues to assess habitats are ascertained within an ecologically relevant context. The use of cues to select habitats is common in many ecosystems: birds use social cues to select superior nesting habitats (Thomson et al. 2003), parasitic wasps and symbiotic ants use visual and olfactory cues to locate hosts (Henneman et al. 2002; Edwards et al. 2006), reef fish larvae use photosensory, olfactory, and auditory cues to find food and refuge on reefs (Tolimieri et al. 2000; Simpson et al. 2004; Gerlach et al. 2007; Job and Bellwood 2007), and sessile intertidal invertebrates use tactile cues to find textured surfaces that reduce exposure to predation and desiccation (Petraitis 1990; Raimondi 1990). If sources of mortality, competition, or resources, etc. vary at the same spatial scale as habitat preference, then selectivity may enhance individual performance.

Marine organisms, which generally have a pelagic larval phase, can use coarse environmental cues, such as light attenuation, to indicate suitable reef or rocky shore habitat. The selection of a specific site for permanent attachment necessarily involves a more refined assessment of habitat quality. For example, many sessile marine taxa detect chemical cues after making contact with the benthos (Rittschof et al. 1998). Conspecific biotic cues, or external biochemicals, indicate habitats where individuals have previously successfully recruited [e.g., barnacles (Raimondi 1988), mussels (Bertness and Grosholz 1985) and damselfish (Booth 1992)]. Heterospecific biotic cues can either induce or inhibit settlement (Steinberg et al. 2002), but the link between the cues from other species and habitat quality is often indirect and more difficult to demonstrate (Thomson et al. 2003; Parejo et al. 2005). For example, abalone (Roberts 2001) and conch (Stoner et al. 1996) metamorphose in response to metabolites from various species of algae. These biotic cues may either indicate resource abundance (Daume et al. 1999) or refuge from predators (Shepherd and Turner 1985).

For settling propagules unable to distinguish between habitat type (e.g., plant seeds or algal spores), facilitation from nearby residents can also enhance recruitment. Facili- tation is typically defined as the ability for a resident species to ameliorate localized environmental conditions, thus permitting recruitment (settlement, growth, and survival) of an inferior species (Bertness 1991; Gomez-Aparicio et al. 2005; Brooker et al. 2008). Evidence for facilitation is most common in systems that have "harsh" environmental conditions where the stress-tolerant facilitator provides an otherwise limiting resource (Bertness and Hacker 1994), often as a by-product. But, as biotic (Graff et al. 2007) or abiotic (Maestre et al. 2009) conditions become more benign, as ontogenetic shifts occur (Miriti 2006), or if interacting species are closely related (Valiente-Banuet and Verdu 2008), facilitation may change to competition. For example, in marine systems, mussels facilitate accumulation of biomass for macroalgae by providing ammonium in nitrogen-limited, high-intertidal pools (Bracken 2004), but may otherwise compete for attachment space in the nutrient replete, lower intertidal zone (Enderlein and Wahl 2004). Although algae are incapable of discerning tidal height, these habitat generalists may persist even in harsher upper intertidal habitats if attached near a facilitator. The fate of the facilitator may be compromised as facilitated species, which can be inferior competitors upon arrival, grow and become competitively dominant over time.

Scleractinian corals spend part of their life cycle as pelagic larvae before permanently attaching to the reef. Individuals experience very high mortality in the early post-settlement period because they are susceptible to mortality from roving grazers (urchins and parrotfishes) (Sammarco 1980, 1982; Miller and Hay 1998), overgrowth from fleshy macroalgae (McCook et al. 2001), and smothering from sedimentation (Fabricius and Wolanski 2000; Nugues and Roberts 2003); these processes occur across a variety of spatial scales (hundreds of meters to millimeters). Coral planula larvae may optimize their choice of settlement habitat by using coarse environmental cues (e.g., phototaxis, water pressure, and soluble chemical attractants; Maida et al. 1994; Mundy and Babcock 1998; Raimondi and Morse 2000; Gleason et al. 2009), presumably to enhance growth, survivorship, or reproductive success (Babcock and Mundy 1996), but benefits of habitat selectivity are not always evident at larger spatial scales (Edmunds et al. 2004; Vermeij 2006). Furthermore, there is a paucity of evidence for facilitation of recruitment of hard corals, but evidence exists for chemical cues that promote metamorphosis of planula larvae.

A biotic cue, bound within the cell wall of a few species of crustose coralline alga (CCA) or associated microbial films (Webster et al. 2004), induces many genera of reefbuilding corals to settle and metamorphose at precise locations. To date, the relationship has been examined mainly in laboratory studies (Morse et al. 1996; Heyward and Negri 1999; Raimondi and Morse 2000; Negri et al. 2001; 
Baird and Morse 2004; Harrington et al. 2004). The ecological significance of this heterospecific biotic cue has yet to be placed in a field context where the distribution and abundance of CCA vary and the size of CCA patches is small relative to the reef landscape. Because preferred CCA have weak anti-fouling mechanisms (Harrington et al. 2004), it is unclear whether they merely provide inert, potential attachment sites or whether they indicate habitats that are otherwise beneficial to the growth and survival of young corals or even actively facilitate coral recruitment by altering local conditions for the susceptible larvae.

In this study, I used manipulative field experiments and observations to establish coral preference during recruitment for cue-bearing CCA. I manipulated the provision of the biotic cue (by outplanting, in different orientations, seasoned plates initially colonized by similar relative abundances of different species of CCA) at two sites. At the time of collection, the plates represented natural distributions of various common species of CCA within habitats of varying quality, which were verified with field observations (data not reported). Recruiting corals were exposed to varying light levels and intensities of grazing and were followed through time. Thus, I was able to examine the relative importance of refined biotic cues for coral settlement across varying degrees of habitat quality and to monitor subsequent demographic rates (growth and survival) of coral recruits across substrate types within those habitats.

\section{Materials and methods}

Study area

To assess the ecological consequences of cue use during settlement, I conducted studies in the outer portions of lagoons $(0.8-1.3 \mathrm{~km}$ wide and $\sim 2$ to $3 \mathrm{~m}$ deep) on the north shore of Moorea, French Polynesia (for more details, see Galzin and Pointier 1985). Patch reefs formed by corals mostly in the genera Porites and Montipora dominated the sandy bottom of the lagoon, and several species of Pocillopora and Acropora were also common. Several genera of encrusting coralline algae and macro-algae (e.g., Turbinaria and Sargassum) were dominant on exposed pavement where live corals and sand were absent.

\section{Habitat manipulation}

I explored the patterns and consequences of recruitment to manipulated habitats that offered the full $2 \times 2$ factorial compliment of exposure (to herbivores, predators, and light) and sedimentation (Fig. 1); the abundance of cueinducing CCA varied naturally within each habitat type. Forty pairs of sanded PVC plates $(15 \times 15 \mathrm{~cm})$ that had been pre-conditioned for 1 month to initiate growth of coralline algae were affixed to reef pavement at each site (at least $0.5 \mathrm{~m}$ apart and $10 \mathrm{~cm}$ above the substrate) using threaded, stainless steel rods. To mimic cryptic habitats, spacers $(1 \mathrm{~cm})$ were put between the two plates of each pair (sensu Raimondi and Morse 2000). The "exposed" outer surfaces received ambient light and were subject to predation (from corallivorous fish) and incidental mortality (from herbivorous fish and urchins); these factors could not be disentangled. "Cryptic" surfaces inside the plate pairs were shaded and protected from corallivory and grazing. Twenty of the plate pairs were oriented vertically to create settlement surfaces with relatively low sediment loads (see "Site and habitat characteristics"). The other 20 were oriented horizontally; those plate surfaces facing upwards were subject to greater sediment deposits than those facing downward, even in cryptic spaces. Therefore, all four combinations of exposure and sediment-deposition treatments were created in the experimental habitats (Fig. 1). Habitats were deployed in December 2003 for a period of 3.5 years (i.e., until corals surviving from 2003 reached $\sim 5 \mathrm{~cm}$ diameter) at two sites $(10 \times 10 \mathrm{~m}$ each) located $\sim 0.5 \mathrm{~km}$ apart on either side of Cook's Bay, approximately $200 \mathrm{~m}$ from the reef crest. After the first 6 months $\left(T_{0.5}\right)$, I suspended pairs of plates on rods in individual 10-1 buckets and transported them to the laboratory ( $10 \mathrm{~min}$ by boat) to map coral recruits (see "Coral substratum selection") and annually thereafter $\left(T_{1.5}, T_{2.5}\right.$, and $\left.T_{3.5}\right)$ to analyze coral recruitment, growth, and mortality.

Site and habitat characteristics

Coral recruitment may be driven in part by large-scale (e.g., oceanic currents that affect flux of larvae, or exposure to roving corallivores) or small-scale (e.g., availability of biotic cues, irradiance, or sedimentation) drivers. Though sediment load and exposure to predation should vary predictably within the previously described manipulated habitats, the hydrodynamics and abundance of herbivores and corallivores may have varied between the two sites, potentially affecting larval supply and survival on exposed surfaces. To detect differences in water masses coming over the reef crest that could be associated with larval flux, temperature, salinity, and water level were monitored with an internally recording, pumped, conductivity-temperaturedepth sensor (CTD; SBE-37SMP; Sea-Bird Electronics). The CTDs were attached to a rigid bracket $25 \mathrm{~cm}$ above the bottom and located near the center of each settlement plate array at each site; they sampled every $5 \mathrm{~min}$ for the first year of the study at both sites. To assess abundance of herbivores and corallivores, snorkelers conducted 5-min swimming surveys along six parallel transects $(2 \times 30 \mathrm{~m})$. All transient herbivorous and corallivorous fish (families 


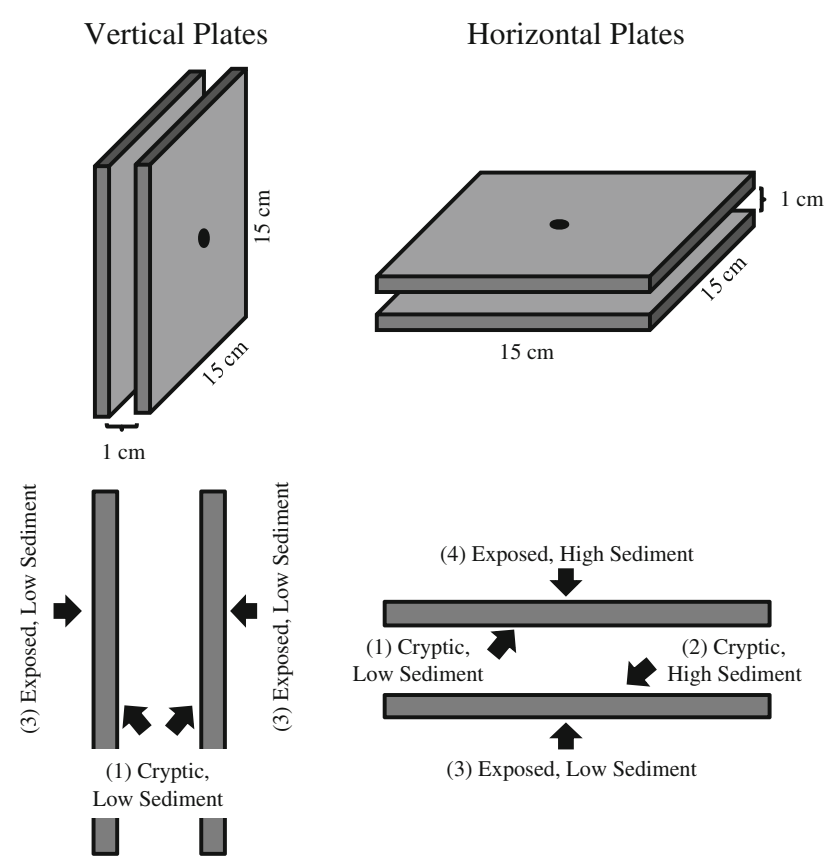

Fig. 1 Schematic of experimental habitats made with sanded PVC plates. Recruitment plates were oriented to create four habitat types: cryptic (inner) and low sediment (vertical plates and downward-facing horizontal plates) (1), cryptic and high sediment (upward-facing horizontal plates) (2), exposed (outer) and low sediment (3), and exposed and high sediment (4)

Scaridae, Acanthuridae, and Chaetodontidae) were counted. Snorkelers also conducted sea urchin surveys (Diadema savignyi and Echinometra mathaei) in $0.25-\mathrm{m}^{2}$ quadrats adjacent to each plate pair ( $n=40$ total per site). A multivariate ANOVA (MANOVA) was used to test for differences in biotic and abiotic characteristics between the two sites after normal distributions and equality of variance was verified.

I assessed differences in photosynthetically active radiation (PAR) among manipulated habitats using a pulse amplitude modulated fluorometer with a light cosine microsensor $\left(180^{\circ}\right.$ collection, calibrated against a Li-Cor LI $1924 \pi$ quantum sensor) at ten locations along a transect (at $1-\mathrm{cm}$ increments) from one edge of the sample plate to the other for each treatment (exposed and cryptic surfaces); PAR values were averaged for each transect. To measure net load, I carefully siphoned $(1-\mathrm{cm}$ aperture) sediments from each plate surface after retrieving them from the field. Sediments were rinsed with $500 \mathrm{ml}$ fresh water, vacuum-filtered onto pre-weighed filter paper (pore size $100 \mu \mathrm{m}$ ), dried at $60^{\circ} \mathrm{C}$ for $12 \mathrm{~h}$, and reweighed; net sediment dry weight was averaged per treatment during each sampling period.

Patterns of coral recruitment among and within habitats

To determine patterns of coral recruitment among habitats and across substrata within habitats, I examined all plate surfaces in the laboratory using a dissecting microscope (100×; Wesco WS7) after 6 months' deployment (at $T_{0.5}$ ). The location of each coral recruit was mapped and identified to family using corallite structure (sensu Babcock et al. 2003). Most recruits were elliptical or circular in shape, so diameter was measured across the longest axis using an eyepiece micrometer. Settlement substratum (CCA species or bare substrate) and recruit condition (alive or dead) were noted; recruits were considered "attached" to CCA if $>50 \%$ of the colony was on top of the crust. Percent cover of encrusting organisms (including species of CCA) was estimated on each plate with a $10 \times 10$ grid of point contacts (1-cm spacing, $n=100$ points). Plates were photographed prior to re-deployment. Differences in density of coral recruits (colonies $\mathrm{m}^{-2}$ ) across sites and surfaces within habitats were assessed using a three-way ANOVA with plates as replicates. Factor I (fixed) was sedimentation regime, factor II (fixed) was exposure, and factor III (random) was site; each factor had two levels. To assess settlement preferences, to particular taxa of CCA, I used Manley's $\alpha$ selectivity indices (Chesson 1983); for this metric, the average index represents "no preference" because recruits would be evenly distributed across each CCA, given its relative abundance. As comparison to the 6-month in situ data reported here, selectivity indices were also calculated for Acropora tenuis settlers in a 3-day laboratory assay that used similar species of CCA (data extracted from Fig. 1, Harrington et al. 2004). Multiple $t$ tests (corrected for family-wide error rates with a sequential Bonferroni procedure) were used to compare each weighted CCA selectivity index to the average index (i.e., no preference). I tested the association between recruitment rate of corals and the availability of coralline algae potentially containing settlement cues with correlation analyses between mean recruit density and percent cover of CCA using plate surfaces $(n=8)$ and sites $(n=2)$ as replicates.

\section{Consequences of substrate selectivity}

Because the plates remained submerged during microscopic inspection and were re-deployed, relative coral survivorship and growth of corals that recruited in the first 6-month cohort could be estimated over time. The plates were retrieved yearly in June $2005\left(T_{1.5}\right), 2006\left(T_{2.5}\right)$ and $2007\left(T_{3.5}\right)$; the same assessment methods were applied to characterize the community composition on each plate surface and coral colony growth and mortality through time. After the initial 6-month period, all recruits budded to form colonies; therefore, growth rates could be estimated as annual change in colony diameter. Colonies were considered dead if no live polyps remained. Differences in growth rates for coral recruits across CCA substrate types were analyzed using a one-way ANOVA with post hoc Tukey 
honest significant difference tests for the first year of growth. Survival data were not analyzed cumulatively, but rather, consecutively for each year to determine if and when substrate selection affected survival of coral recruits. Accordingly, sample size drops with each consecutive year as fewer corals reached the next age or size class. For each time step, contingency tables were used to assess whether the proportion of coral colonies surviving depended upon substrate type.

\section{Results}

Variation in habitat characteristics and patterns of coral recruitment

The two recruitment study sites were separated spatially by Cook's Bay, and their combined biotic and abiotic characteristics varied significantly (MANOVA, Hotelling $T^{2}=10.3$, $P<0.0001)$. Temperature, salinity, and water depth did not vary between the sites, but relative sediment loads were twice as high on the eastern as compared to the western side of the bay (Table 1). The sea urchin D. savignyi was twice as dense on the east (Table 1), while surgeonfishes and corallivorous butterflyfishes were more abundant on the west side of Cook's Bay (Table 1). Nonetheless, communities within the manipulated plate habitats were similar across sites and were dominated by encrusting calcareous algae (45\%), foliose algae (26\%), sponges and ascidians (2-3\%), and mollusks (2-3\%) at the time of first collection. The most notable changes in community structure were those of coral diversity and cover, which grew to as much as $50 \%$ on a given plate over the course of the study.

Significant variation in environmental variables occurred between manipulated habitats as a result of plate orientation and exposure. PAR was significantly reduced on the cryptic surfaces compared to the exposed ones $(t=8.19, d f=69$, $P<0.0001)$, with ambient irradiance on the exposed surfaces $\left[391.7 \pm 63.7 \mu \mathrm{mol}\right.$ photons $\mathrm{s}^{-1} \mathrm{~m}^{-2} \quad($ mean $\pm \mathrm{SE})$, $n=10$ ] nearly tenfold higher than that reaching the cryptic habitats $\left(41.7 \pm 14.3 \mu \mathrm{mol}\right.$ photons s$\left.{ }^{-1} \mathrm{~m}^{-2}, n=10\right)$. Sediment load was tripled on the upwards-facing horizontal plates $(n=80)$ as compared to vertical plates and undersides of horizontal plates ( $n=240$ surfaces) in the first sampling period (Welch's $t$ test for unequal sample size, $t=5.26, d f=98, P<0.0001)$; the relative net dry sediment weights were consistent across all sampling periods. "High" sediment treatments had, averaged across 3 years, $17.04 \pm 1.26 \mathrm{~g} \mathrm{~m}^{-2}$ year $^{-1}$ deposited on each plate surface, while "low" sediment treatments only received $5.85 \pm 0.87 \mathrm{~g} \mathrm{~m}^{-2}$ year $^{-1}$.

Of the 383 total coral recruits detected during the first sampling period $\left(T_{0.5}\right), 90 \%$ were pocilloporids with the remainder belonging to the genera Acropora (4.4\%), Porites $(4.7 \%)$, and Montastrea, Favia, or Siderastrea $(<1 \%)$. Densities of pocilloporid recruits tended to be greater to the west of Cook's Bay (mean $5.0 \pm 0.6$ recruits per plate pair, $n=206)$ than to the east $(3.7 \pm 0.5, n=147)$, though these differences were not significant $(t=1.72, \quad d f=159$, $P=0.086)$. The diameters for all coral recruits were $<5 \mathrm{~mm}$ after 6 months, and averaged $2.7 \pm 0.1 \mathrm{~mm}$ across the longest axis and were smaller than the average CCA $(11.8 \pm 0.9 \mathrm{~mm})$.

Pocilloporid recruit densities were highest on cryptic, low sediment load surfaces $\left(100.0 \pm 9.3\right.$ recruits $\mathrm{m}^{-2}$, $n=120$ ) and almost no pocilloporids were recruited on high sedimentation surfaces (Fig. 2a). Six times as many pocilloporids recruited to cryptic as to exposed plate surfaces $\left(16.7 \pm 3.6\right.$ recruits $\left.\mathrm{m}^{-2}, n=80\right)$, but only when sediment deposition was reduced. Accordingly, there was a significant interaction between exposure (to herbivores and ambient PAR) and sediment load per plate surface
Table 1 Biotic and abiotic habitat characteristics (mean $\pm \mathrm{SE}$ ) of the two study sites (Cook's Bay East and Cook's Bay West) on the north shore of Moorea, French Polynesia. Given are densities of key taxa of sea urchins and herbivorous and corallivorous fishes

$* P<0.05, * * * * P<0.0001$

\begin{tabular}{lcccc}
\hline & Cook's Bay West & Cook's Bay East & $t$ ratio & $P$ value \\
\hline Biotic characteristics (no. $60 \mathrm{~m}^{-2}$ ) & & & & \\
Echinometra mathei & $85.5 \pm 15.1$ & $82.8 \pm 20.4$ & 0.0 & 0.922 \\
Diadema savignyi & $13.8 \pm 4.2$ & $35.4 \pm 7.8$ & 5.2 & $0.025^{*}$ \\
Acanthuridae & $26.0 \pm 1.3$ & $18.8 \pm 0.6$ & 23.0 & $<0.0001^{* * * *}$ \\
Scaridae & $1.4 \pm 0.5$ & $1.8 \pm 0.5$ & 1.2 & 0.270 \\
Chaetodontidae & $2.8 \pm 0.5$ & $1.6 \pm 0.2$ & 5.4 & $0.024^{*}$ \\
Abiotic characteristics & & & & \\
Sediment load $\left(\mathrm{g} \mathrm{m}^{-2}\right.$ year $^{-1}$ ) & $6.5 \pm 0.7$ & $12.7 \pm 0.7$ & 24.2 & $<0.0001^{* * * *}$ \\
Salinity (p.p.t.) & $28.58 \pm 0.55$ & $28.57 \pm 0.55$ & & \\
Temperature $\left({ }^{\circ} \mathrm{C}\right)$ & $35.85 \pm 0.09$ & $35.74 \pm 0.20$ & & \\
Water depth $(\mathrm{m})$ & $2.20 \pm 0.08$ & $2.05 \pm 0.08$ & & \\
\hline
\end{tabular}



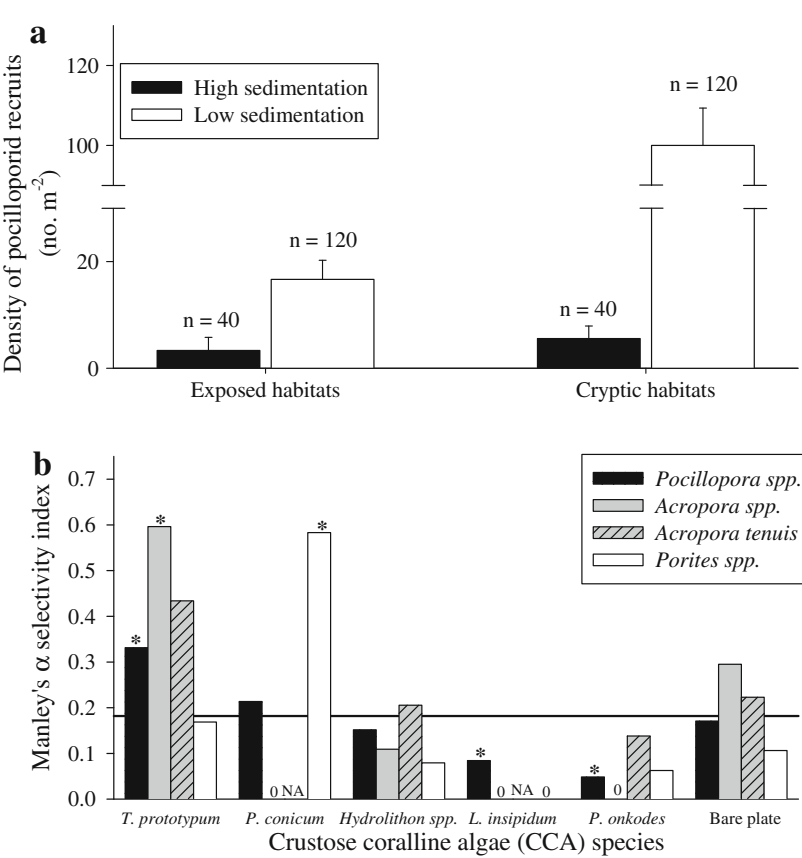

Fig. 2 a Density (no. $\mathrm{m}^{-2}$ ) of pocilloporid coral recruits (mean $+\mathrm{SE}$ ) in exposed or cryptic habitats with high $\left(14.67 \pm 1.33 \mathrm{~g} \mathrm{~m}^{-2}\right.$ year $\left.^{-1}\right)$ or low $\left(7.56 \pm 0.44 \mathrm{~g} \mathrm{~m}^{-2}\right.$ year $\left.^{-1}\right)$ sedimentation after 6 months. Sample sizes $(n)$ reported above each bar. b Selectivity indices (Manley's $\alpha$ ) calculated for each of the possible substrate choices for coral recruits from the genus Pocillopora (black bars), Acropora (gray bars), and Porites (white bars) after 6 months in situ within cryptic habitats that had low sedimentation rates and for Acropora tenuis settlers (hatched bars) after 3 days in the Harrington et al. (2004) laboratory assay. Substrate options were either a particular species of crustose coralline algae (CCA) or unoccupied space on the PVC plate ("bare plate"). The solid line represents random or passive settlement $(\alpha=0.1667)$. NA A. tenuis not used in the laboratory assay; 0 selectivity index value of zero; asterisk significantly different than random at $\alpha=0.05$, indicating preference if above the line or avoidance if below

$(F=12.60, d f=2,312, P<0.0001)$, as well as a significant influence of each main effect (exposure and sedimentation; $F \geq 6.3, d f=2,312, P \leq 0.002)$. Effects of habitat were consistent across sites $(P>0.25)$, thus, data from both sites were pooled for the remaining analyses.

\section{Coral substratum selection}

Only one of the five common species of CCA positively influenced the recruitment rate of pocilloporid and acroporid corals (Fig. 2b). Within the cryptic, low sediment habitats, recruits of both coral families attached to the nongeniculate encrusting red alga Titanoderma prototypum significantly more often than expected (Table 2); colonies were typically found adhered to the center of the CCA patch. Recruits of poritid corals were attached to a second species of CCA, Pneophyllum conicum, more often than expected (Fig. 2b; Table 2). Two other common species of CCA, Porolithon onkodes and Lithophyllum insipidum, had the opposite influence: corals were associated with these species less often than expected. Corals recruited to all remaining coralline algae and bare plate space at random, or as often as expected by chance given the cover of substrate. Based on these results, the CCA were combined into three functional categories: "preferred", "neutral", or "avoided".

Pocilloporid recruitment rates were positively related to the abundance (percent cover) of preferred CCA at both sites $\left(r=0.83, F_{1,12}=26.59, P=0.0002\right.$; Fig. 3a). T. prototypum was most abundant in cryptic habitats that experienced relatively low sedimentation, also where the largest proportions of corals recruited, and virtually absent elsewhere (Fig. 3). Percent cover of avoided CCA was unrelated to abundance of pocilloporid recruits $(r=-0.44$, $F_{1,12}=2.75, P=0.123$; Fig. 3b). Both $P$. onkodes and L. insipidum were most abundant on exposed surfaces and were also sensitive to sedimentation (Fig. 3).

Consequences of substrate selectivity

Many (37\%) of the pocilloporids that originally recruited to the cryptic, low sediment habitats survived during the first sampling interval $\left(T_{0.5}-T_{1.5}\right)$, in contrast to very low survival $(<1 \%)$ in any other habitat. Thus, the relationship

Table 2 Multiple $t$ tests of selectivity indices for each substrate type against an average selectivity (representing random settlement) for the three most common genera of coral

\begin{tabular}{|c|c|c|c|c|c|c|c|c|c|}
\hline \multirow[t]{2}{*}{ Substrate type } & \multicolumn{3}{|c|}{ Pocillopora } & \multicolumn{3}{|c|}{ Acropora } & \multicolumn{3}{|c|}{ Porites } \\
\hline & $t$ ratio & $P$ value & $P_{\text {adj }}$ & $t$ ratio & $P$ value & $P_{\text {adj }}$ & $t$ ratio & $P$ value & $P_{\text {adj }}$ \\
\hline Titanoderma prototypum & 4.69 & 0.005 & $0.032 *$ & 4.39 & 0.007 & $0.041 *$ & 0.02 & 0.982 & 0.982 \\
\hline Pneophyllum conicum & 0.81 & 0.453 & 0.867 & 1.70 & 0.149 & 0.554 & 4.83 & 0.005 & $0.028^{*}$ \\
\hline Hydrolithon spp. & 1.24 & 0.270 & 0.809 & 0.59 & 0.581 & 0.581 & 1.01 & 0.359 & 0.736 \\
\hline Lithophyllum insipidum & 3.46 & 0.018 & $0.072 \dagger$ & 1.70 & 0.149 & 0.554 & 1.93 & 0.111 & 0.445 \\
\hline Porolithon onkodes & 4.37 & 0.006 & $0.032 *$ & 1.70 & 0.149 & 0.554 & 1.21 & 0.282 & 0.734 \\
\hline Bare plate & 0.60 & 0.713 & 0.867 & 1.13 & 0.247 & 0.554 & 0.70 & 0.515 & 0.765 \\
\hline
\end{tabular}

Sequential Bonferroni tests were used to adjust the $P$ value to correct for family-wide error rate; both raw $P$ values and Bonferroni adjusted $P$ values are reported $\left(P_{\text {adj }}\right)$

$\dagger P<0.1, * P<0.05$ 


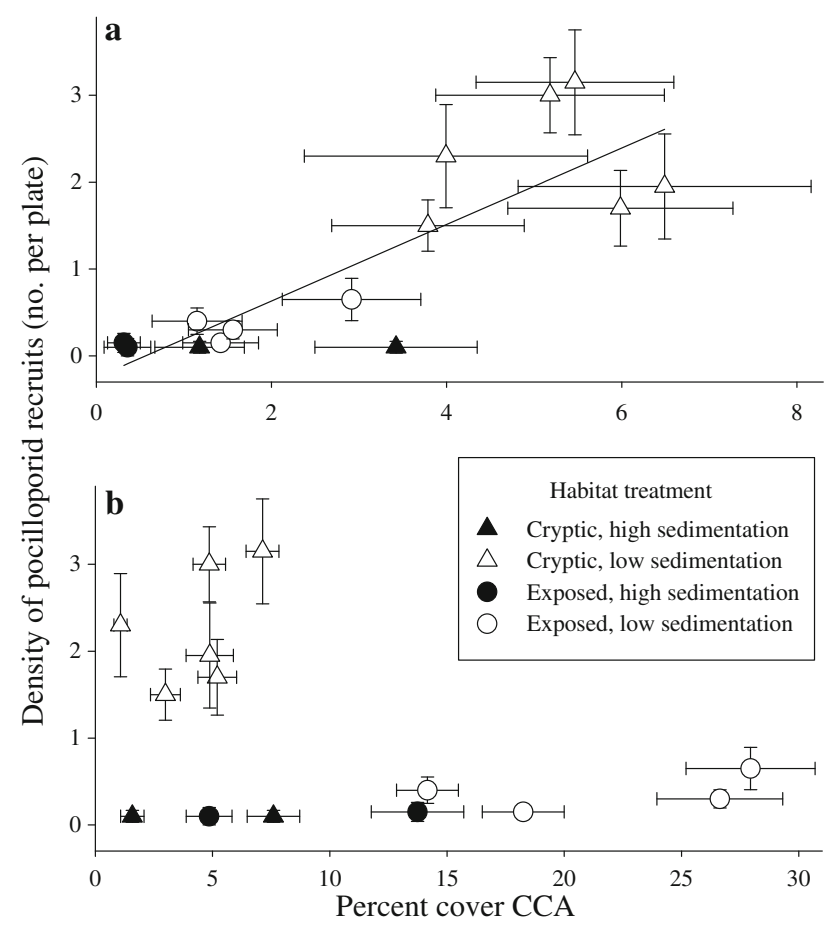

Fig. 3 The relationship between recruitment rates of pocilloporids (no. per plate surface, $225 \mathrm{~cm}^{2}$ ) and the in situ percent cover of a preferred CCA (Titanoderma prototypum; $y=44.03 x-0.25 ; r=0.83$; $P=0.0002$ ) and $\mathbf{b}$ avoided CCA (Porolithon onkodes and Lithophyllum insipidum $)$ across all habitat treatments $(r=-0.44 ; P=0.12)$

between coral performance (measured both as growth and survival) and settlement substrate was examined only within the cryptic habitats. The growth of pocilloporid recruits depended significantly upon substrate type during the first year (ANOVA F $=3.81, d f=3,108, P=0.012$ ). Pocilloporid corals that recruited to preferred CCA experienced growth rates similar to those on neutral CCA or on bare plate space; corals on avoided CCA grew significantly slower than all other corals (Fig. 4a). By the second and third years following recruitment, growth could not be assessed for individuals that had settled to avoided CCA as there were no survivors; $\sim 30 \%$ coral recruits disappeared and $\sim 70 \%$ recruits either died before or after being overgrown by the avoided CCA. Growth was equivalent on preferred, neutral, and bare space substrata within each year for the remainder of the experiment, but decreased in magnitude across each consecutive year of the study.

On average, the largest proportion of recruits of pocilloporid corals, irrespective of settlement substrata, died in the year following the initial sampling $(0.69 \pm 0.8)$ as compared to subsequent years $(0.50 \pm 0.17$ and $0.38 \pm 0.06)$. All of the coral recruits found attached to preferred CCA and bare space in the first sampling period $\left(T_{0.5}\right)$ were alive, but only 79 and $67 \%$ of the pocilloporids were alive on neutral and avoided CCA, respectively. In the first year following the initial sampling, mortality rates were significantly different across substrate types $\left(\chi^{2}=21.5, d f=3\right.$, $268, P<0.0001)$. Pocilloporids experienced $\sim 30 \%$ reduction in mortality rate when associated with $T$. prototypum as compared to the next "best" substrata (Fig. 4b). The mortality rates for pocilloporid corals associated with the preferred CCA were consistently low for each year of the study and averaged $0.36 \pm 0.06$. Pocilloporid corals experienced the highest mortality rates on avoided CCA; in fact, no pocilloporids survived on $P$. onkodes or $L$. insipidum through the second year of this study. Pocilloporid corals on the neutral CCA and bare plate substrata experienced greater mortality rates than those settled on preferred CCA in the first year, but mortality was nearly halved and not significantly different than on preferred CCA thereafter [(2006) $T_{2.5}, \chi^{2}=0.41, d f=2,112, P=0.81 ;(2007) T_{3.5}$, $\left.\chi^{2}=1.13, d f=2,77, P=0.57\right]$. The proportion of live pocilloporid colonies associated with $T$. prototypum increased from 0.56 to 0.76 (and of live acroporids from 0.27 to 0.67 ) over the duration of the study as colonization of alternative substrata failed.

\section{Discussion}

The use of cues, either environmental or biotic, for selection of appropriate habitat for reproduction, resource acquisition, or permanent attachment during settlement is a common behavioral adaptation to heterogeneous landscapes across a variety of ecosystems. Many sessile taxa are known to use specific biotic cues for settlement in marine systems (Keough and Raimondi 1995), and often these cues augment growth, survival, or fecundity for newly attached individuals. While coarse light cues during the recruitment process for coral planula larvae can optimize settler growth while minimizing exposure to harmful UV rays (Gleason et al. 2006), sedimentation, or overgrowth by algae (Maida et al. 1994; Vermeij and Sandin 2008), the consequences of fine-scale biotic settlement cues remain poorly understood within an ecologically relevant context. Thus far, the only observed benefit for corals using biotic settlement cues has been provision of an inert attachment site free from antifouling defenses in laboratory studies (Harrington et al. 2004), but here I have shown that the relative distribution, abundance, and species-specific characteristics of the preferred CCA combine to facilitate coral recruitment within a natural environment.

Reliance on biotic cues will depend on the balance of costs and benefits incurred upon arrival to the selected habitat. The benefit for species that respond to conspecific cues released from established colonizers (e.g., barnacles and damselfish) is clear as the previous cohort can indicate habitats that are conducive to survival (Raimondi 1988; 
Schmitt and Holbrook 2002), though new arrivals may experience intraspecific competition, density-dependent mortality (Schmitt and Holbrook 1996, 2000; Vermeij and Sandin 2008) or increased transmission of diseases (Janzen 1970; Connell 1971) as overcrowding occurs. Species that respond to heterospecific cues will benefit only if the indicator species reliably indicate habitat quality without strong interspecific competition for resources (Parejo et al. 2005; Forsman et al. 2008), provide habitat for the newcomers (Henneman et al. 2002; Edwards et al. 2006), or space settlers so as to reduce intraspecific competition and/or enhance fecundity (Raimondi and Morse 2000). For example, the post-larvae of abalone that metamorphose in response to cues from CCA will consume diatoms that can otherwise smother the algal crusts (Daume et al. 2000); in this case, the heterospecific cue is mutually beneficial. Ecological "traps" for species responding to heterospecific cues, due to disparate resource needs or unequal predator susceptibility, will occur if the niches of cue users and providers are mismatched (Stamps and Krishnan 2005). However, facilitation can mitigate post-settlement costs arising from use of ecologically incongruous heterospecific cues. If the cue-containing species ameliorates an environmental stressor, then the impact of competition for resources at the settlement location or the ecological mismatch between heterospecific cues and settlers may be negligible. Therefore, the costs of competing for resources with adults or using an inconsistent indicator may be balanced by other services offered from using the cue.

Provision of a heterospecific biotic cue, by the CCA $T$. prototypum, may provide two distinct benefits to corals during recruitment: indication of suitable habitat and facilitation. In this study and others (Sato 1985), recruitment patterns of pocilloporid corals were consistently driven by a combination of exposure to sedimentation, predation (direct or incidental) and/or light. Because the distribution of preferred CCA, T. prototypum, mirrored that of pocilloporid recruits (both the coral and CCA were most abundant on cryptic plate surfaces with low sedimentation rates), the cue may confirm selection of habitat based on coarse environmental cues (e.g., light attenuation). The positive relationship between the abundance of preferred CCA and density of coral recruits may reflect common habitat criteria for both $T$. prototypum and pocilloporid corals, unrecorded early mortality of coral recruits on exposed surfaces, or increased recruitment rates as a result of biotic cue availability.

To tease apart these processes post hoc, settlement preferences of acroporids during this field experiment (6 months) were compared to those of A. tenuis, estimated in a short-term settlement preference assay (3 days) performed in the lab (Harrington et al. 2004). Because field recruitment preferences were identical to those of the short- term laboratory settlement assay (Fig. 1b), selectivity was probably driven in part by settlement behavior and availability of the cue. However, the strength of selectivity (and avoidance) appeared to be greater after 6 months in situ than in the 3-day laboratory assay (Fig. 1b). The apparent elevation or diminution of preference in situ may reflect the increased and decreased relative post-settlement survival on preferred and avoided CCA, respectively. Thus, unrecorded differential survival of coral recruits and behavioral selection of substrate could not be completely disentangled in this study. This result highlights the importance of conducting settlement assays in situ to understand the combined effects of larval settlement behavior and location of biotic cues.

This field-based study contributes to our knowledge of the relative importance of biotic cues for coral larval settlement on a reef. Larvae of reef-building corals may be using a hierarchy of coarse and precise cues detectable at different scales for habitat selection. While oceanic currents, light, and changes in pressure may direct a recruit towards the substrate of a reef, the presence of biotic cues will refine attachment site location and initiate metamorphosis. The orientation and location of the cue enhanced its importance for recruit performance by localizing recruits in an optimal, cryptic habitat for growth and survival. The existence of cryptic locations in a reef matrix can be ephemeral due to disturbances that open space, and the presence of a slowgrowing algal crust could signify the longevity and specificity of appropriate habitat that coarse environmental cues cannot. Because $T$. prototypum is not a common CCA in Moorea (Fig. 3a, $x$-axis), it may be a conservative cue whose absence does not automatically imply poor habitat quality (Raimondi 1988). Larvae of pocilloporid corals will settle in the absence of the cue (Baird and Morse 2004), but the relative importance of the cue might not have been detected in these studies because preferred CCA species were not included in the choice experiments. Hierarchical surveys of coral recruitment across reefs and within crevices with greater abundances of $T$. prototypum would be informative and indicate the prevalence of the reliance on the cue.

The added benefit of facilitation for coral recruits that settle on the preferred CCA within the optimal habitat may favor use of the cue. The cue facilitated recruitment of pocilloporid corals not only by presumably initiating metamorphosis of planula larvae, but also by enhancing growth and survival of colonizers. By the end of the study, more than $75 \%$ of the surviving coral juveniles had been associated with $T$. prototypum because the fitness costs for settling on the wrong surface (either avoided CCA or bare space) were very high. Pocilloporid corals that evaded settling on P. onkodes or L. insipidum may have circumvented potential sloughing or overgrowth from these avoided CCA 

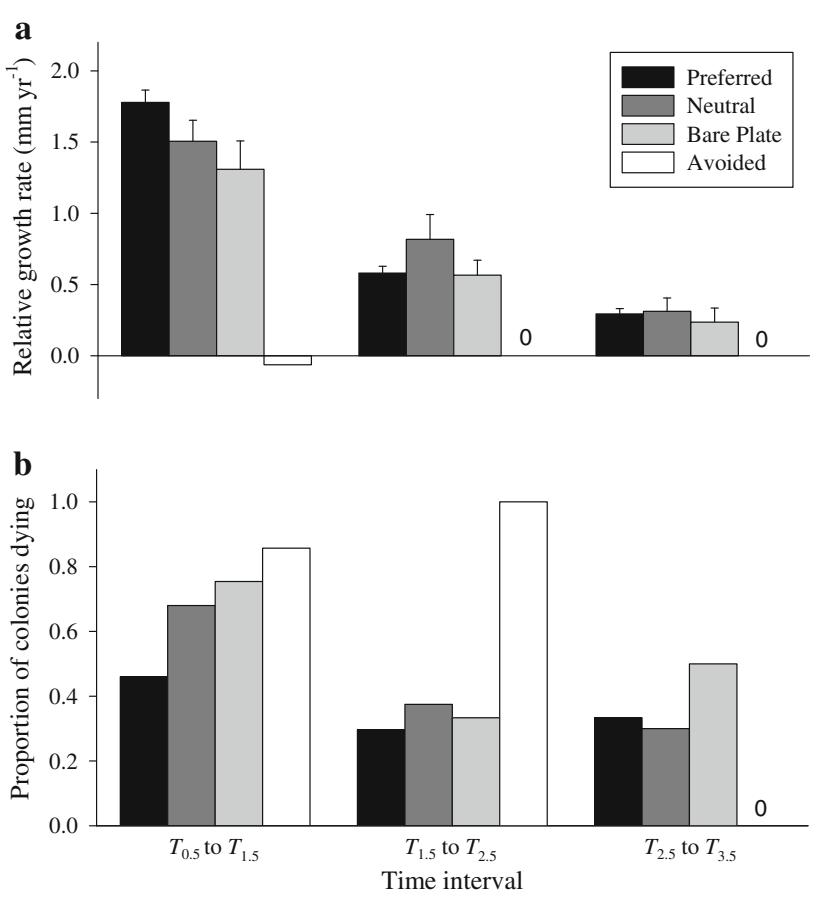

Fig. 4 Growth and mortality rates for pocilloporid corals categorized by original settlement substrate within each annual time interval since initial recruitment [year $1\left(T_{0.5}\right.$ to $\left.T_{1.5}\right)$, year $2\left(T_{1.5}\right.$ to $\left.T_{2.5}\right)$, year $3\left(T_{2.5}\right.$ to $\left.T_{3.5}\right)$ ]. Data are only from cryptic, low sedimentation habitats. a Growth rate per pocilloporid colony estimated as annual log change in diameter (mean + SE); 0 (above bars) indicates a rate of zero. b Annual mortality rate estimated as proportion of the 2004 cohort of recruits dying within each annual interval. Preferred Corals settled on the coralline algae $T$. prototypum, Neutral coralline algae are Hydrolithon spp. and P. conicum, Bare plate previously unoccupied space on the PVC plate, Avoided coralline algae are both P. onkodes and L. insipidum

(Harrington et al. 2004), while those settling on preferred CCA had reduced mortality compared to even those on bare plate (Fig. 4b). The differences in growth and survival rates of pocilloporid colonies associated with $T$. prototypum were attributed solely to settlement substratum preference as all individuals analyzed were from optimal habitats. Facilitation ceased by the second year of recruitment, probably because the coral grew away from or over the preferred CCA. Also, increased dimensionality of the coral could have exposed the colony to stressors that $T$. prototypum could no longer mitigate. Although the benefit of the biotic cue is relatively short-lived, it comes at a critical period in the life cycle when mortality is highest (Miller et al. 2000; Edmunds 2004; Vermeij 2006; Vermeij and Sandin 2008). This system of ontogenetically specific facilitation is similar to nurse plants in desert or salt marsh ecosystems where the facilitator is required for the vulnerable seedling stage and not thereafter (Valiente-Banuet and Verdu 2008).

The exact mechanism of facilitation was not examined in this study, but there are several possible ways that CCA can influence recruit growth and survival. The oxygen conditions can vary at the surface of the CCA (Kaspar 1992) and may influence abiotic conditions surrounding the metamorphosing larvae. CCA more likely ameliorate fine-scale conditions related to biotic interactions than reduce abiotic stressors. The unique morphology of T. prototypum (Woelkerling 1988) and its lack of sloughing defenses may encourage a particular microbial consortia to associate with its crust and thus reduce exposure to infectious bacteria for newly metamorphosed coral colonies (Smith et al. 2006). $T$. prototypum may also limit exposure to competitive foliose or filamentous algae via allelopathy (Kim et al. 2004), thereby creating micro-refugia for vulnerable coral recruits. Though facilitation is often argued to explain recruitment of sensitive plants to stressful habitats in desert and salt marsh ecosystems (Brooker et al. 2008), this form of "biotic" facilitation where the facilitator reduces or changes biotic interactions with potential competitors is rarely explored.

As the coral recruits expanded, facilitation became irrelevant (Fig. 4) and the interaction with CCA likely became competitive; thus the consequence of attracting settlers for CCA may be dire. However, many species of CCA are able to tolerate overgrowth (Dethier 2001; Bulleri 2006; Underwood 2006). Although there seems to be little obvious benefit to the CCA for inducing settlement of corals, ammonium release from sessile invertebrates can influence algal productivity (Williamson and Rees 1994); coral waste may provide limiting nutrients for CCAs. Also, particular species of CCA, such as the preferred $T$. prototypum, are easily photo-inhibited (Leukart 1994) and the shade provided by growing coral colonies might improve CCA productivity. It is important to note that the exact chemical composition of the CCA-derived settlement cue for corals has not yet been elucidated as it has been for larvae of abalone (Morse et al. 1979). Thus, it is unclear whether T. prototypum seeks to attract coral larvae or does so inadvertently because the cue is merely a by-product that corals have adapted to exploit.

The facultative, heterospecific cue that early successional, branching corals (i.e., pocilloporids and acroporids) use for recruitment has many important implications for coral and CCA abundance patterns and for recovery from disturbance. The assemblage and relative abundances of CCA occupying space on the reef prior to coral larval delivery may influence the rate of coral replenishment and reef accretion. Because CCA often tolerate even large disturbance events, such as outbreaks of Ancanthaster plancii or storms (Becerro et al. 2006), the assemblage mosaic of CCA may determine the rate of reef recovery. The inability of previous field studies to detect effects of habitat selection for coral recruitment may be due the spatial scale at which habitat suitability was defined and the lack of taxonomic 
specificity for settlement substrates; studies that relate recruitment success to specific attachment sites may be more informative (e.g., this study and Vermeij 2006; Vermeij and Sandin 2008). Interactions among CCA and their relative abundances, the degree to which incoming larvae depend upon biotic settlement cues, and the relative ability of the CCA to facilitate or inhibit coral recruitment may influence the distribution and abundance of adult coral colonies. Identifying the key species of CCA categorized as "facilitators" or "inhibitors" in pristine and degraded reef ecosystems may lend insight to resilience of these reefs to future anthropogenic or natural disturbances.

Acknowledgments I thank J. Hench for CTD deployment and analysis, M. Schmitt for photography of plate surfaces, R. Steneck for assistance with identification of crustose coralline algae, and J. Smith for editorial advice. My thesis advisor, R. Schmitt, and committee members, S. Holbrook, P. J. Edmunds, and R. M. Nisbet provided invaluable guidance. This research was supported by grants from the US National Science Foundation (OCE 04-17412) and the International Society for Reef Studies and the Ocean Conservancy, and gifts from the W. M. Keck Foundation and the Gordon and Betty Moore Foundation. This is a contribution of the Moorea Coral Reef Long-term Ecological Research and is contribution number 186 of the U. C. Berkeley Gump Research Station.

Open Access This article is distributed under the terms of the Creative Commons Attribution Noncommercial License which permits any noncommercial use, distribution, and reproduction in any medium, provided the original author(s) and source are credited.

\section{References}

Babcock R, Mundy C (1996) Coral recruitment: consequences of settlement choice for early growth and survivorship in two scleractinians. J Exp Mar Biol Ecol 206:179-201

Babcock RC, Baird AH, Piromvaragorn S, Thomson DP, Willis BL (2003) Identification of scleractinian coral recruits from IndoPacific reefs. Zool Stud 42:211-226

Baird AH, Morse ANC (2004) Induction of metamorphosis in larvae of the brooding corals Acropora palifera and Stylophora pistillata. Mar Freshwater Res 55:469-472

Becerro MA, Bonito V, Paul VJ (2006) Effects of monsoon-driven wave action on coral reefs of Guam and implications for coral recruitment. Coral Reefs 25:193-199

Bertness MD (1991) Interspecific interactions among high marsh perennials in a New England salt marsh. Ecology 72:125-137

Bertness MD, Grosholz E (1985) Population dynamics of the ribbed mussel, Geukensia demissa: the costs and benefits of an aggregated distribution. Oecologia 67:192-204

Bertness MD, Hacker SD (1994) Physical stress and positive associations among marsh plants. Am Nat 144:363-372

Booth DJ (1992) Larval settlement patterns and preferences by domino damselfish Dascyllus albisella Gill. J Exp Mar Biol Ecol 155:85-104

Botero L, Atema J (1982) Behavior and substrate selection during larval settling in the lobster Homarus americanus. J Crustac Biol 2:59-69

Bracken MES (2004) Invertebrate-mediated nutrient loading increases growth of an intertidal macroalga. J Phycol 40:1032-1041

Brooker RW, Maestre FT, Callaway RM, Lortie CL, Cavieres LA, Kunstler G, Liancourt P, Tielborger K, Travis JMJ, Anthelme F,
Armas C, Coll L, Corcket E, Delzon S, Forey E, Kikvidze Z, O1ofsson J, Pugnaire F, Quiroz CL, Saccone P, Schiffers K, Seifan M, Touzard B, Michalet R (2008) Facilitation in plant communities: the past, the present, and the future. J Ecol 96:18-34

Bulleri F (2006) Duration of overgrowth affects survival of encrusting coralline algae. Mar Ecol Prog Ser 321:79-85

Chesson J (1983) The estimation and analysis of preference and its relationship to foraging models. Ecology 64:1297-1304

Connell JH (1971) In: de Boer PJ, Gradwell GR (eds) Dynamics of populations. Center for Agricultural Publishing and Documentation, Wageningen, The Netherlands, pp 298-312

Daume S, Brand-Gardner S, Woelkerling WJ (1999) Preferential settlement of abalone larvae: diatom films vs. non-geniculate coralline red algae. Aquaculture 174:243-254

Daume S, Krsinich A, Farrell S, Gervis M (2000) Settlement, early growth and survival of Haliotis rubra in response to different algal species. J Appl Phycol 12:479-488

Dethier MN, Steneck RS (2001) Growth and persistence of diverse intertidal crusts: survival of the slow in a fast-paced world. Mar Ecol Prog Ser 223:89-100

Edmunds PJ (2004) Juvenile coral population dynamics track rising seawater temperature on a Caribbean reef. Mar Ecol Prog Ser 269:111-119

Edmunds PJ, Bruno JF, Carlon DB (2004) Effects of depth and microhabitat on growth and survivorship of juvenile corals in the Florida Keys. Mar Ecol Prog Ser 278:115-124

Edwards DP, Hassall M, Sutherland WJ, Yu DW (2006) Assembling a mutualism: ant symbionts locate their host plants by detecting volatile chemicals. Insectes Sociaux 53:172-176

Enderlein P, Wahl M (2004) Dominance of blue mussels versus consumer-mediated enhancement of benthic diversity. J Sea Res $51: 145-155$

Fabricius KE, Wolanski E (2000) Rapid smothering of coral reef organisms by muddy marine snow. Estuar Coast Shelf Sci 50:115-120

Forsman JT, Hjernquist MB, Taipale J, Gustafsson L (2008) Competitor density cues for habitat quality facilitating habitat selection and investment decisions. Behav Ecol 19:539-545

Galzin R, Pointier JP (1985) Moorea Island, Society Archipelago. In: Proceedings of the 5th International Coral Reef Symposium, vol 1, pp 73-102

Gerlach G, Atema J, Kingsford MJ, Black KP, Miller-Sims V (2007) Smelling home can prevent dispersal of reef fish larvae. Proc Natl Acad Sci USA 104:858-863

Gleason DF, Edmunds PJ, Gates RD (2006) Ultraviolet radiation effects on the behavior and recruitment of larvae from the reef coral Porites astreoides. Mar Biol 148:503-512

Gleason DF, Danilowicz BS, Nolan CJ (2009) Reef waters stimulate substratum exploration in planulae from brooding Caribbean corals. Coral Reefs 28:549-554

Gomez-Aparicio L, Gomez JM, Zamora R, Boettinger JL (2005) Canopy vs. soil effects of shrubs facilitating tree seedlings in Mediterranean montane ecosystems. J Veg Sci 16:191-198

Graff P, Aguiar MR, Chaneton EJ (2007) Shifts in positive and negative plant interactions along a grazing intensity gradient. Ecology 88:188-199

Harrington L, Fabricius K, De'Ath G, Negri A (2004) Recognition and selection of settlement substrata determine post-settlement survival in corals. Ecology 85:3428-3437

Henneman ML, Dyreson EG, Takabayashi J, Raguso RA (2002) Response to walnut olfactory and visual cues by the parasitic wasp Diachasmimorpha juglandis. J Chem Ecol 28:2221-2244

Heyward AJ, Negri AP (1999) Natural inducers for coral larval metamorphosis. Coral Reefs 18:273-279

Janzen DH (1970) Herbivores and number of tree species in tropical forests. Am Nat 104:501-528 
Job S, Bellwood DR (2007) Ultraviolet photosensitivity and feeding in larval and juvenile coral reef fishes. Mar Biol 151:495-503

Kaspar HF (1992) Oxygen conditions on surfaces of coralline red algae. Mar Ecol Prog Ser 81:97-100

Keough MJ, Raimondi PT (1995) Responses of settling invertebrate larvae to bioorganic films: effects of different types of films. J Exp Mar Biol Ecol 185:235-253

Kim J, Choi JS, Kang SE, Cho JY, Jin HJ, Chun BS, Hong YK (2004) Multiple allelopathic activity of the crustose coralline alga Lithophyllum yessoense against settlement and germination of seaweed spores. J Appl Phycol 16:175-179

Leukart P (1994) Field and laboratory studies on depth dependence, seasonality and light requirement of growth in three species of crustose coralline algae (Corallinales, Rhodophyta). Phycologia 33:281-290

Maestre FT, Callaway RM, Valladares F, Lortie CJ (2009) Refining the stress-gradient hypothesis for competition and facilitation in plant communities. J Ecol 97:199-205

Maida M, Coll JC, Sammarco PW (1994) Shedding new light on scleractinian coral recruitment. J Exp Mar Biol Ecol 180:189-202

McCook LJ, Jompa J, Diaz-Pulido G (2001) Competition between corals and algae on coral reefs: a review of evidence and mechanisms. Coral Reefs 19:400-417

Miller MW, Hay ME (1998) Effects of fish predation and seaweed competition on the survival and growth of corals. Oecologia 113:231-238

Miller MW, Weil E, Szmant AM (2000) Coral recruitment and juvenile mortality as structuring factors for reef benthic communities in Biscayne National Park, USA. Coral Reefs 19:115-123

Miriti MN (2006) Ontogenetic shift from facilitation to competition in a desert shrub. J Ecol 94:973-979

Monkkonen M, Hardling R, Forsman JT, Tuomi J (1999) Evolution of heterospecific attraction: using other species as cues in habitat selection. Evol Ecol 13:91-104

Moran MJ (1985) Distribution and dispersion of the predatory intertidal gastropod Morula marginalba. Mar Ecol Prog Ser 22:41-52

Morris DW (2003) Toward an ecological synthesis: a case for habitat selection. Oecologia 136:1-13

Morse DE, Hooker N, Duncan H, Jensen L (1979) Gamma-aminobutyric acid, a neurotransmitter, induces planktonic abalone larvae to settle and begin metamorphosis. Science 204:407-410

Morse ANC, Iwao K, Baba M, Shimoike K, Hayashibara T, Omori M (1996) An ancient chemosensory mechanism brings new life to coral reefs. Biol Bull 191:149-154

Mundy CN, Babcock RC (1998) Role of light intensity and spectral quality in coral settlement: implications for depth-dependent settlement? J Exp Mar Biol Ecol 223:235-255

Negri AP, Webster NS, Hill RT, Heyward AJ (2001) Metamorphosis of broadcast spawning corals in response to bacteria isolated from crustose algae. Mar Ecol Prog Ser 223:121-131

Nugues MM, Roberts CM (2003) Coral mortality and interaction with algae in relation to sedimentation. Coral Reefs 22:507-516

Parejo D, Danchin E, Aviles JM (2005) The heterospecific habitat copying hypothesis: can competitors indicate habitat quality? Behav Ecol 16:96-105

Petraitis PS (1990) Direct and indirect effects of predation, herbivory and surface rugosity on mussel recruitment. Oecologia 83:405413

Raimondi PT (1988) Settlement cues and determination of the vertical limit of an intertidal barnacle. Ecology 69:400-407

Raimondi PT (1990) Patterns, mechanisms, consequences of variability in settlement and recruitment of an intertidal barnacle. Ecol Monogr 60:283-309

Raimondi PT, Morse ANC (2000) The consequences of complex larval behavior in a coral. Ecology 81:3193-3211
Rittschof D, Forward RB, Cannon G, Welch JM, McClary M, Holm ER, Clare AS, Conova S, McKelvey LM, Bryan P, Van Dover CL (1998) Cues and context: larval responses to physical and chemical cues. Biofouling 12:31-44

Roberts R (2001) A review of settlement cues for larval abalone ( $\mathrm{Hal}$ iotis spp.). J Shellfish Res 20:571-586

Rosenzweig ML (1981) A theory of habitat selection. Ecology 62:327335

Sammarco PW (1980) Diadema and its relationship to coral spat mortality: grazing, competition, and biological disturbance. J Exp Mar Biol Ecol 45:245-272

Sammarco PW (1982) Echinoid grazing as a structuring force in coral communities: whole reef manipulations. J Exp Mar Biol Ecol 61:31-55

Sato M (1985) Mortality and growth of juvenile coral Pocillopora damicornis (Linnaeus). Coral Reefs 4:27-33

Schmitt RJ, Holbrook SJ (1996) Local-scale patterns of larval settlement in a planktivorous damselfish-do they predict recruitment? Mar Freshwater Res 47:449-463

Schmitt RJ, Holbrook SJ (2000) Habitat-limited recruitment of coral reef damselfish. Ecology 81:3479-3494

Schmitt RJ, Holbrook SJ (2002) Correlates of spatial variation in settlement of two tropical damselfishes. Mar Freshwater Res 53:329-337

Shachak M, Brand S (1988) Relationship among settling, demography and habitat selection: an approach and a case study. Oecologia 76:620-626

Shepherd SA, Turner JA (1985) Studies on southern Australian abalone (genus Haliotis). VI. Habitat preference, abundance and predators of juveniles. J Exp Mar Biol Ecol 93:285-298

Simpson SD, Meekan MG, McCauley RD, Jeffs A (2004) Attraction of settlement-stage coral reef fishes to reef noise. Mar Ecol Prog Ser 276:263-268

Smith JE, Shaw M, Edwards RA, Obura D, Pantos O, Sala E, Sandin SA, Smriga S, Hatay M, Rohwer FL (2006) Indirect effects of algae on coral: algae-mediated, microbe-induced coral mortality. Ecol Lett 9:835-845

Smoothey AF, Chapman MG (2007) Small-scale variability in the dispersion of the sea urchin Heliocidaris erythrogramma among boulders. Mar Ecol Prog Ser 340:89-99

Stamps J, Krishnan VV (2005) Nonintuitive cue use in habitat selection. Ecology 86:2860-2867

Steinberg PD, De Nys R, Kjelleberg S (2002) Chemical cues for surface colonization. J Chem Ecol 28:1935-1951

Stoner AW, Ray M, Glazer RA, McCarthy KJ (1996) Metamorphic responses to natural substrata in a gastropod larva: decisions related to postlarval growth and habitat preference. J Exp Mar Biol Ecol 205:229-243

Storch D, Frynta D (1999) Evolution of habitat selection: stochastic acquisition of cognitive clues? Evol Ecol 13:591-600

Thomson RL, Forsman JT, Monkkonen M (2003) Positive interactions between migrant and resident birds: testing the heterospecific attraction hypothesis. Oecologia 134:431-438

Tolimieri N, Jeffs A, Montgomery JC (2000) Ambient sound as a cue for navigation by the pelagic larvae of reef fishes. Mar Ecol Prog Ser 207:219-224

Underwood AJ (2006) Why overgrowth of intertidal encrusting algae does not always cause competitive exclusion. J Exp Mar Biol Ecol 330:448-454

Valiente-Banuet A, Verdu M (2008) Temporal shifts from facilitation to competition occur between closely related taxa. J Ecol 96:489494

Vermeij MJA (2006) Early life-history dynamics of Caribbean coral species on artificial substratum: the importance of competition, growth and variation in life-history strategy. Coral Reefs 25:59-71 
Vermeij MJA, Sandin SA (2008) Density-dependent settlement and mortality structure the earliest life phases of a coral population. Ecology 89:1994-2004

Webster NS, Smith LD, Heyward AJ, Watts JEM, Webb RI, Blackall LL, Negri AP (2004) Metamorphosis of a scleractinian coral in response to microbial biofilms. Appl Environ Microbiol 70:12131221
Williamson JE, Rees TAV (1994) Nutritional interaction in an algabarnacle association. Oecologia 99:16-20

Woelkerling WJ (1988) The coralline red algae: an analysis of the genera and subfamilies of nongeniculate Corallinaceae. Oxford University Press, London 